\title{
Sexual Behaviours among Oil and Gas Workers in the Niger-Delta Region of Nigeria: Assessing the Impact of Comprehensive HIV/AIDS Prevention Programs
}

\section{Onoja AJ', Sanni OF${ }^{2}$, Abiodun $\mathrm{PA}^{3}$, Shaibu $\mathrm{J}^{1}$, Onoja $\mathrm{SI}^{1}$, Adamu I', Oguche $\mathrm{D}^{1}$}

${ }^{1}$ Research Department, African Health Project, Abuja, Nigeria, ${ }^{2}$ Departement of Public Health, Triune Biblical University Global Extension, NY, USA, ${ }^{3}$ Department of National Integrated Specimen Referral Network, AXIOS International, Utako, FCT, Abuja, Nigeria

\section{ABSTRACT}

Introduction: The major means of transmitting sexual-related diseases including HIV is through unprotected sexual activities. This study aimed to assess the impact of comprehensive HIV prevention interventions on the sexual behaviour of oil and gas workers in Bonny Island, a rural community of Rivers State, Nigeria.

Methods: This is a cross-sectional-quantitative study that employed a structured questionnaire among oil and gas workers aged 15 - 49 years in Bonny Island. The information collected from February to April 2012 (after a threeyear HIV prevention and control intervention programs) includes the socio-demographics; age, gender, education, occupation, marital status and data related to sexual behaviours. Data were analysed using IBM-SPSS version 25.0 .

Results: There were 419 respondents each in baseline and post-intervention surveys. The rate of unprotected sex among respondents at baseline was $82.1 \%$ as compared to $20.3 \%$ after the intervention, odds ratio- 18.02 (95\% Cl-12.76-25.45; $\mathrm{P}<0.0001)$. Sixty-one (14.6\%) exchanged sex for gifts in the baseline and $12.4 \%$ in the post-intervention. At the baseline, $5.0 \%$ used condoms in the last sexual intercourse as compared to $26.0 \%$ in the post-intervention; odds ratio - 6.66 (95\% Cl-4.08-10.88; $\mathrm{P}<0.0001)$. Factors associated with condoms use include sex, age, education, duration in the community, marital status, and living with spouses $(p<0.01)$.

Conclusion: There was a significant positive impact of a comprehensive intervention programme on the sexual behaviour of oil and gas workers in the rural community of Rivers State, Nigeria. However, regular interventions in rural communities towards the prevention of the spread of STIs and HIV are needed in Nigeria.

Key words: HIVIAIDS, Intervention programme, Sexual behaviours, STIs

\section{Introduction}

$\mathrm{T}$ he vulnerability to Human Immunodeficiency Virus (HIV) and sexually transmitted infections (STIs)

DOI: https://doi.org/10.3126/ijosh.v11i2.36371

Conflicts of interest: None Supporting agencies: None

Date of submission: 09.04.2021

Date of acceptance: 06.06.2021

Date of publication: 20.06.2021

\section{Corresponding Author}

Dr. Johnson A. Onoja

Chief Executive Officer,

African Health Project, Plot 7, Ellicott Street, Kubwa Ext 3,

Kubwa, Abuja FCT, Nigeria.

Phone: 2348037879939.

E-mail: onojaali@yahoo.com

ORCID - https://orcid.org/0000-0002-6764-5685 have been reportedly high among industrial workers, especially the migrants. ${ }^{1-4}$ The widespread of HIV and STI has also been described as the most important determinant of the burden of HIV in Sub-Saharan Africa. ${ }^{5,6}$

Some factors associated with unsafe behavioural changes such as unsafe sexual activities, excessive drinking, migration, mobility, and separation from family. ${ }^{1,7}$

The risk of heterosexual HIV transmission is greater among workers in rural communities due to their lack of access to HIV treatment and prevention or

\section{(c) (7) \&}

This journal is licensed under a Creative Commons AttributionNon Commercial 4.0 International License. 
inadequate facilities, exposure to sex workers and work situations. ${ }^{1}$ In sub-Saharan Africa, particularly the rural communities, the definition of sexual activities is determined by cultural belief, social and economic context. Discussing sex with the opposite sex in the public is seen as taboo. ${ }^{8}$ Both sexes (men and women) are at equal risk of HIV infection with about $80 \%$ of the risk associated with transmission through heterosexual activities. ${ }^{8,9}$

High risky sexual behaviour among industrial workers has been reported in some parts of the world. The factors associated with such risky behaviour include being immigrant, drunkenness, and mobility and selfcare challenges. ${ }^{1,10}$

The widespread transmission of HIV and STIs in Nigeria, especially among the adolescents in rural communities have been associated with risky sexual behaviour and attitudes, which is mostly due to economic necessities to trade sex for financial rewards. ${ }^{11}$ Some are even compelled into sexual engagements by men who are involved in multiple sexual relationships. ${ }^{5}$ Without exaggeration, the NigerDelta area of Nigeria has been noted for high sexual activities and is partly due to the increased population of emigrant staff of oil and gas industries. ${ }^{11}$ Due to the migration of wealthy oil and gas workers to the NigerDelta region without their families, they use their wealth to entice the poor villagers to engage in unsafe sexual activities with them. ${ }^{12}$ Consistent use of condom has been considered the most appropriate behavioural indicators used to assess the success of HIV-preventive interventions, particularly among key populations such as female sex workers, and people who inject drugs. ${ }^{13}$ Several individuals and community-based behavioural, biomedical and systemic interventions are commonly employed in the prevention of HIV and support for people living with the infection. ${ }^{13-17} \mathrm{~A}$ study conducted in sub-Saharan Africa on interventions to prevent STI/HIV found an increased use of condom among intervention participants as compared to those without interventions. ${ }^{18}$ Another study conducted in South Africa found that interventions helped in delaying sexual activities and increased use of condoms among sexually active youths as compared to the groups without interventions. ${ }^{19}$ The objective of this study is to assess the impacts of intervention programmes on the sexual behaviour of the oil and gas workers in Bonny Island, Rivers State, Nigeria.

\section{Methods}

This was a survey conducted in Bonny Island which is an oil-rich rural community of Rivers State, Nigeria. Similar to other parts of the world, the presence of a liquefied natural gas producing company (NLNG) in the community has attracted Nigerians from different tribes as well as foreign professional to work and live in Bonny, either permanently or temporarily.

Because Bonny Island had a high rate of HIV in this community, a baseline survey was conducted in the year 2006 by the Society for Family Health (SFH) and the data obtained was used as a base data for three years (2008-2011) HIVIAIDS prevention intervention programme carried out in the community by African Health Projects (AHP). ${ }^{20}$

Interventions carried out in Bonny for three years included HIV voluntary counselling and testing (VCT), awareness creation through radio and television programs such as 'Jann Kunne film' (radio and television drama in local language), 'AIDS and You', 'Ireti alaafia (a program to educate the community on HIV)', 'One thing at a time', a radio drama program called 'Gari muna fata', a television program called 'Odejinjin', and a radio and television drama program called 'Abule oloke merin'. ${ }^{21,22}$ Other interventions include condoms made available in clinics and pharmacies for free, townhall and workplace meetings, HIV awareness creation using posters and handbills, free-referrals for HIV positive people and follow-ups programs. The interventions lasted for three years after which another survey was conducted on the sexual behaviours of the oil and gas workers to compare the outcomes of the intervention with their sexual behaviours before the interventions.

The estimated 1500 population of oil and gas workers aged 15-49 in the community was used to determine the sample size by applying Slovin's formula is $\mathrm{n}=\frac{N}{\left(1+N e^{2}\right)\left(1+N e^{2}\right)}$

$\mathrm{n}$ represents sample size, $\mathrm{N}=$ population of oil and gas workers $=1500$, and $\mathrm{e}=$ marginal error of $4 \%=0.04$.

This formula was used because the prevalence of HIV or sexual behaviour among oil and gas workers was unknown at the time of this study.

$\mathrm{n}=\frac{1500}{\left(1+1500 \times 0.04^{2}\right)\left(1+1500 \times 0.04^{2}\right)}$ 
The pre-intervention sample size was calculated as 441 but 419 (95.0\%) participated in the pre-intervention study. The sample size for the post-intervention study was estimated in line with the proportion of the number of respondents in the study before the interventions.

Data was collected between February and April, 2012 through the use of a structured questionnaire and only workers aged 15 - 49 years were included because these are the active labour force. Trained researcher assistants were assigned to the oil and gas companies and questionnaires were distributed to only those who volunteered to take part in the study. The data collected include the level of unprotected sex, transactional sex, and the use of a condom. The completed questionnaires were collected and verified for proper filling. Data collected were analysed with IBM-SPSS version 25.0 for Windows. Descriptive statistics were performed and the results were tabulated. Chi-square test was used to find the significance between variables setting the significant level at $5 \%$.

The ethical approval number NHREC/01/01/200728/07/2011 was obtained from the Federal Ethics committee. Respondents were also informed about the study and their consents to voluntarily participate in the study was obtained before questionnaires were administered to them. No information that can be used to identify any of the respondents was collected and all participants were assured of the confidentiality of their personal information.

\section{Results}

The study comprised 838 respondents with 419 $(50.0 \%)$ from each survey with a response rate of $95 \%$ (419 of 444 ) of the expected total sample size. The surveys comprised 419 oil and gas workers in the pre-intervention and post-intervention studies, making a total of 838 respondents. Since the interval between both surveys was six years and no information that can be used to identify any of the oil and gas workers was collected, the study could not ascertain the number of baseline respondents that participated in the postintervention survey.

The proportions of males and females were $52.7 \%$ and $47.3 \%$ in the baseline and $54.4 \%$ and $45.6 \%$ post intervention. The majority of respondents in baseline were between $25-34$ years old $(45.6 \%)$ whereas the majority of post intervention respondents were 35 years old or higher $(43.7 \%)$. The highest proportions of respondents from both surveys attained secondary education $48.7 \%$ and $55.8 \%$. While the majority of baseline respondents $(52.7 \%)$ have been away from their families for about 12 months before the survey, only $34.6 \%$ have been away in the pre-intervention study. More than half of the respondents both in the pre and post intervention (74.1\%-baseline and $65.5 \%$-intervention) lived in the community with their spouses while $55.1 \%$ and $60.4 \%$ for baseline and intervention respectively see their families more than once every month as shown in Table 1.

As shown in Table 2, $82.1 \%$ of the baseline participants have had unprotected sex three months before the survey and this was significantly higher than $20.3 \%$ in the post intervention survey; the odds of engaging in unprotected sex at the baseline was 18.02 (95\% $\mathrm{Cl}-12.76-25.45 ; \mathrm{P}<0.001)$ times higher than the post intervention. The rate of unprotected sex was 29.79 (95\% Cl-17.11-51.87; $\mathrm{P}<0.0001)$ times higher among females in baseline than the intervention. Also, male respondents at the baseline were 12.18 (95\% Cl-7.8019.00; $P<0.0001)$ more likely to have unprotected sex than those in the intervention. The rate of unprotected sex increased with increase in age in both surveys but significantly higher at the baseline with $70.7 \%$ among respondents aged $15-24$ and $88.4 \%$ among 35 years when compared to post intervention with $11.6 \%$ and $15.8 \%$ for the same age groups respectively $(p<0.0001)$. The rate of unprotected sex was also higher in baseline across marital status (single 68.5\%, married $90.7 \%$ ) than in the post-intervention (single-14.6\%, married-27.8\%). Married people without intervention were 25.40 (95\% Cl-14.87-43.38) times more likely to have unprotected sex than their counterparts with interventions. Singles were12.67 (95\% Cl-7.50-21.41) times likely to have unprotected sex at the baseline than interventions.

As shown in Table 3, the rate of transactional sex was low in both surveys but there was a slight reduction post intervention (12.4\%) as compared to $14.6 \%$ in the baseline $(p>0.05)$. This slight reduction in transactional sex was observed across gender, age, marital status, level of education, and the number of times respondents see their spouses. However, a significant reduction was observed among respondents who have stayed in the community for four or more years with an odds ratio of 3.20 (95\% Cl-1.35-7.59; $\mathrm{P}=0.008)$. Also, married people who did not live with their spouses in the community were $3.32(95 \% \mathrm{Cl}-1.42-7.71 ; \mathrm{P}=$ 
0.005) times more likely to engage in transactional sex than those who lived in the community with their spouses.

Table 4 shows the proportion of those who used condom in their last sexual intercourse, both at the baseline and post intervention. While only $5.0 \%$ used condoms during last sexual intercourse in the baseline survey, $26.0 \%$ used condom in the intervention. The odds of using condoms after the interventions was 6.66 (95\% Cl-4.08-10.88; $\mathrm{P}<0.0001)$ higher than without the interventions. The Table also shows significantly higher rates of using condoms in the post-intervention across all socio demographic profiles as compared to the baseline $(p<0.05)$. Male respondents with interventions were 6.97 (95\% Cl-3.56-13.67; $\mathrm{P}<0.0001)$ more likely to use condoms than those without interventions. Also, respondents who attained post-secondary education and were exposed to the interventions were 33.09 (95\% Cl-7.88-139.01; $\mathrm{P}<0.0001)$ more likely to use a condom during sex than their counterparts at the baseline. Those who have stayed in Bonny for 1-3 years and had the interventions were $9.09(95 \%-\mathrm{Cl}-$ $4.35-19,01 ; \mathrm{P}<0.0001)$ more likely to use a condom than those without interventions. The odds of using condom among singles with interventions was 14.37 (95\% Cl-7.09-29.14; $\mathrm{P}<0.0001$ ) as compared to singles at the baseline.

Table 1: Socio-demographic profiles of respondents

\begin{tabular}{|c|c|c|}
\hline Respondents Profile & Baseline $(n=419)$ & Post-Intervention $(n=419)$ \\
\hline \multicolumn{3}{|l|}{ Sex of respondent } \\
\hline Male & $221(52.7)$ & $228(54.4)$ \\
\hline Female & $198(47.3)$ & $191(45.6)$ \\
\hline \multicolumn{3}{|l|}{ Age group } \\
\hline 15-24yrs & $99(23.6)$ & $112(26.7)$ \\
\hline 25-34yrs & $191(45.6)$ & $124(29.6)$ \\
\hline 35yrs-above & $129(30.8)$ & $183(43.7)$ \\
\hline \multicolumn{3}{|l|}{ Marital status } \\
\hline Single & $203(49.2)$ & $164(39.1)$ \\
\hline Ever married & $216(50.8)$ & $255(60.9)$ \\
\hline \multicolumn{3}{|l|}{ Highest level of education } \\
\hline No formal education/Primary & $88(21.0)$ & $29(6.9)$ \\
\hline Secondary & $204(48.7)$ & $234(55.8)$ \\
\hline Post secondary & $127(30.3)$ & $156(37.3)$ \\
\hline \multicolumn{3}{|l|}{ Length of stay in Bonny } \\
\hline Less than a year & $99(23.6)$ & $83(19.8)$ \\
\hline $1-3$ years & $129(30.8)$ & $187(44.6)$ \\
\hline 4yrs and above & $191(45.6)$ & $149(35.6)$ \\
\hline \multicolumn{3}{|c|}{ Stayed away from home in the past 12 months } \\
\hline Yes & $221(52.7)$ & $145(34.6)$ \\
\hline No & $198(47.3)$ & $274(65.4)$ \\
\hline \multicolumn{3}{|c|}{ Live with the spouse in the community (married) } \\
\hline Yes & $160(74.1)$ & $167(65.5)$ \\
\hline No & $56(25.9)$ & $88(34.5)$ \\
\hline \multicolumn{3}{|c|}{ How often do you see your spouse (Married) } \\
\hline Not more than once a month & $97(44.9)$ & $101(39.6)$ \\
\hline More than once a month & $119(55.1)$ & $154(60.4)$ \\
\hline
\end{tabular}


Onoja AJ et al.

Table 2: Respondent who have had unprotected sex in the last three months

\begin{tabular}{|c|c|c|c|c|c|c|}
\hline \multirow{2}{*}{ Respondents Profile } & \multicolumn{2}{|c|}{ Baseline $(n=419)$} & \multicolumn{2}{|c|}{ Intervention (n=419 } & \multirow[b]{2}{*}{ Odds ratio $(95 \% \mathrm{CI})$} & \multirow[b]{2}{*}{ P-Value } \\
\hline & Yes (\%) & Total & Yes (\%) & Total & & \\
\hline \multicolumn{7}{|l|}{ Sex of respondent } \\
\hline Male & $170(76.9)$ & 221 & $49(21.5)$ & 228 & $12.18(7.80-19.00)$ & $<0.0001$ \\
\hline Female & $173(87.4)$ & 198 & $36(18.8)$ & 191 & $29.79(17.11-51.87)$ & $<0.0001$ \\
\hline \multicolumn{7}{|l|}{ Age group } \\
\hline $15-24 y r s$ & $70(70.7)$ & 99 & $13(11.6)$ & 112 & $18.38(8.92-37.85)$ & $<0.0001$ \\
\hline $25-34 y r s$ & $156(81.7)$ & 191 & $16(12.9)$ & 124 & $30.09(15.86-570.8)$ & $<0.0001$ \\
\hline 35yrs-above & $114(88.4)$ & 129 & $29(15.8)$ & 183 & $40.36(20.68-78.8)$ & $<0.0001$ \\
\hline \multicolumn{7}{|l|}{ Marital status } \\
\hline Single & $139(68.5)$ & 203 & $24(14.6)$ & 164 & $12.67(7.50-21.41)$ & $<0.0001$ \\
\hline Ever married & $196(90.7)$ & 216 & $71(27.8)$ & 255 & $25.40(14.87-43.38)$ & $<0.0001$ \\
\hline \multicolumn{7}{|l|}{ Highest education } \\
\hline No education/primary & $73(83.0)$ & 88 & $7(24.1)$ & 29 & $15.30(5.54-42.24)$ & $<0.0001$ \\
\hline Secondary & $181(88.7)$ & 204 & $33(14.1)$ & 234 & $47.93(27.13-84.67)$ & $<0.0001$ \\
\hline Post-secondary & $98(77.2)$ & 127 & $11(7.1)$ & 156 & 44.55 (21.26-93.35) & $<0.0001$ \\
\hline \multicolumn{7}{|l|}{ Length of stay in Bonny } \\
\hline Less than a year & 79 (79.8) & 99 & $14(16.9)$ & 83 & $19.47(9.14-41.11)$ & $<0.0001$ \\
\hline $1-3$ years & $105(81.4)$ & 129 & $31(16.6)$ & 187 & $22.02(12.23-39.62)$ & $<0.0001$ \\
\hline 4yrs and above & $159(83.3)$ & 191 & $18(12.1)$ & 149 & $36.16(19.41-67.36)$ & $<0.0001$ \\
\hline \multicolumn{7}{|c|}{ Stayed away from home in the past 12 months } \\
\hline Yes & $185(86.9)$ & 221 & $36(24.8)$ & 145 & $20.01(11.57-34.59)$ & $<0.0001$ \\
\hline No & $167(86.5)$ & 198 & $48(17.5)$ & 274 & $30.24(18.02-50.74)$ & $<0.0001$ \\
\hline \multicolumn{7}{|c|}{ Live with spouses in the community (married only) } \\
\hline Yes & $141(88.1)$ & 160 & $25(15.0)$ & 167 & $42.15(22.2-80.00)$ & $<0.0001$ \\
\hline No & $42(75.0)$ & 56 & $21(23.9)$ & 88 & $9.57(4.49-20.85)$ & $<0.0001$ \\
\hline \multicolumn{7}{|c|}{ How often do you see your spouse (married) } \\
\hline Not more than once a month & $80(82.5)$ & 97 & $12(11.9)$ & 101 & $34.90(15.71-77.54)$ & $<0.0001$ \\
\hline More than once a month & $113(95.0)$ & 119 & $46(29.9)$ & 154 & $44.22(18.15-107.75)$ & $<0.0001$ \\
\hline Total & 344 (82.1) & 419 & $85(20.3)$ & 419 & 18.02 (12.76-25.45) & $<0.0001$ \\
\hline
\end{tabular}

Table 3: Distribution of respondents who exchange sex for gifts in the last three months

\begin{tabular}{|c|c|c|c|c|c|c|}
\hline \multirow{2}{*}{ Respondents Profile } & \multicolumn{2}{|c|}{ Baseline } & \multicolumn{2}{|c|}{ Intervention } & \multirow{2}{*}{$\begin{array}{l}\text { Odds ratio }(95 \% \\
\text { CI) }\end{array}$} & \multirow{2}{*}{ P-value } \\
\hline & Yes (\%) & Total & Yes (\%) & Total & & \\
\hline \multicolumn{7}{|l|}{ Sex of respondent } \\
\hline Male & $27(12.2)$ & 221 & $27(11.8)$ & 228 & $1.04(0.59-1.83)$ & 0.903 \\
\hline Female & $34(17.1)$ & 198 & $25(13.1)$ & 191 & $1.37(0.79-2.41)$ & 0.263 \\
\hline \multicolumn{7}{|l|}{ Age group } \\
\hline $15-24 y r s$ & $17(17.2)$ & 99 & $16(14.3)$ & 112 & $1.24(0.59-2.62)$ & 0.565 \\
\hline $25-34 y r s$ & $23(12.0)$ & 191 & $14(11.3)$ & 124 & $1.08(0.53-2.18)$ & 0.840 \\
\hline 35yrs-above & $21(16.3)$ & 129 & $22(12.0)$ & 183 & $1.42(0.75-2.71)$ & 0.284 \\
\hline \multicolumn{7}{|l|}{ Marital status } \\
\hline Single & $31(15.3)$ & 203 & $21(12.8)$ & 164 & $1.23(0.68-2.23)$ & 0.501 \\
\hline Ever married & $30(13.9)$ & 216 & $31(12.2)$ & 255 & $1.17(0.68-2.00)$ & 0.577 \\
\hline \multicolumn{7}{|l|}{ Highest education } \\
\hline No education/primary & $17(19.3)$ & 88 & $6(20.7)$ & 29 & $0.92(0.32-2.60)$ & 0.872 \\
\hline Secondary & $31(15.2)$ & 204 & $33(14.1)$ & 234 & $1.09(0.64-1.86)$ & 0.747 \\
\hline Postsecondary & $13(10.2)$ & 127 & $13(8.3)$ & 156 & $1.25(0.56-2.81)$ & 0.582 \\
\hline
\end{tabular}




\section{Length of stay in Bonny}

$\begin{array}{lcccccc}\text { Less than a year } & 14(14.1) & 99 & 8(9.6) & 83 & 1.54(0.61-3.88) & 0.356 \\ 1-3 \text { years } & 21(16.3) & 129 & 33(17.6) & 187 & 0.91(0.50-1.65) & 0.751 \\ \text { 4yrs and above } & 26(13.6) & 191 & 7(4.7) & 149 & 3.20(1.35-7.59) & 0.008^{*}\end{array}$

\section{Stayed away from home in the past 12 months}

$\begin{array}{lllllll}\text { Yes } & 36(16.9) & 213 & 32(22.1) & 145 & 0.72(0.42-1.22) & 0.222 \\ \text { No } & 25(13.0) & 193 & 20(7.3) & 274 & 1.89(1.02-3.51) & 0.044^{*}\end{array}$

Live with the spouse in the community (married respondents)

$\begin{array}{lcccccc}\text { Yes } & 12(7.5) & 160 & 14(8.4) & 167 & 0.89(0.40-1.97) & 0.768 \\ \text { No } & 18(32.1) & 56 & 11(12.5) & 88 & 3.32(1.42-7.71) & 0.005^{*}\end{array}$

\begin{tabular}{ccccccc} 
How often do you see your spouse? (married) & & & & & \\
Not more than once a month & $19(19.6)$ & 97 & $16(15.8)$ & 101 & $1.29(0.62-2.69)$ & 0.490 \\
More than once a month & $11(9.2)$ & 119 & $9(5.8)$ & 154 & $1.64(0.66-4.10)$ & 0.289 \\
\hline Total & $\mathbf{6 1 ( 1 4 . 6 )}$ & $\mathbf{4 1 9}$ & $\mathbf{5 2 ( 1 2 . 4 )}$ & $\mathbf{4 1 9}$ & $\mathbf{1 . 2 0}(\mathbf{0 . 8 1 - 1 . 7 9 )}$ & $\mathbf{0 . 3 6 3}$ \\
\hline
\end{tabular}

* Significant at $p<0.05$.

Table 4: Use of condom in the last sexual intercourse

\begin{tabular}{|c|c|c|c|c|c|c|}
\hline \multirow{2}{*}{ Characteristics } & \multicolumn{2}{|c|}{ Baseline $(n=419)$} & \multicolumn{2}{|c|}{ Intervention $(n=419)$} & \multirow{2}{*}{ Odds ratio $(95 \% \mathrm{Cl})$} & \multirow{2}{*}{ P-value } \\
\hline & Yes (\%) & Total & Yes (\%) & Total & & \\
\hline \multicolumn{7}{|l|}{ Sex of respondents } \\
\hline Male & $11(5.0)$ & 221 & $61(26.8)$ & 228 & 6.97 (3.56-13.67) & $<0.0001$ \\
\hline Female & $10(5.1)$ & 198 & $48(25.1)$ & 191 & $6.31(3.09-12.90)$ & $<0.0001$ \\
\hline \multicolumn{7}{|l|}{ Highest education } \\
\hline No formal/primary & $2(2.3)$ & 88 & $10(34.5)$ & 29 & $22.63(4.58-111.81)$ & $<0.0001$ \\
\hline Secondary & $17(8.3)$ & 204 & $45(19.2)$ & 234 & $2.61(1.45-4.74)$ & $<0.0001$ \\
\hline Post-secondary & $2(1.6)$ & 127 & $54(34.6)$ & 156 & $33.09(7.88-139.01)$ & $<0.0001$ \\
\hline \multicolumn{7}{|l|}{ Length of stay in Bonny } \\
\hline Less than a year & $2(2.0)$ & 99 & $10(12.0)$ & 83 & $6.64(1.41-31.25)$ & 0.0165 \\
\hline $1-3$ years & $9(4.7)$ & 191 & $58(31.0)$ & 187 & $9.09(4.35-19,01)$ & $<0.0001$ \\
\hline 4yrs and above & $10(7.8)$ & 129 & $41(27.5)$ & 149 & $4.52(2.16-9.46)$ & $<0.0001$ \\
\hline \multicolumn{7}{|l|}{ Marital status } \\
\hline Single & $10(4.9)$ & 203 & $70(42.7)$ & 164 & $14.37(7.09-29.14)$ & $<0.0001$ \\
\hline Ever married & $11(5.1)$ & 216 & $39(15.3)$ & 255 & $3.36(1.68-6.75)$ & $<0.0001$ \\
\hline \multicolumn{7}{|c|}{ Stayed away from home in the past 12 months } \\
\hline Yes & $15(7.0)$ & 213 & $47(32.4)$ & 145 & $6.63(3.37-11.88)$ & $<0.0001$ \\
\hline No & $6(3.1)$ & 193 & $62(22.6)$ & 274 & $9.11(3.85-21.56)$ & $<0.0001$ \\
\hline \multicolumn{7}{|c|}{ Live with the spouse in the community (married) } \\
\hline Yes & $4(2.5)$ & 160 & $12(7.2)$ & 167 & $3.02(0.95-9.57)$ & $<0.0001$ \\
\hline No & $7(12.5)$ & 56 & $27(30.7)$ & 88 & $3.10(1.24-7.72)$ & $<0.0001$ \\
\hline \multicolumn{7}{|c|}{ How often do you see your spouse (married) } \\
\hline Not more than once a month & $8(8.2)$ & 97 & $25(24.8)$ & 101 & $3.66(1.56-8.59)$ & $<0.0001$ \\
\hline More than once a month & $3(2.5)$ & 119 & $14(9.1)$ & 154 & $3.87(1.08-13.78)$ & $<0.0001$ \\
\hline Total & $21(5.0)$ & 419 & $109(26.0)$ & 419 & $6.66(4.08-10.88)$ & $<0.0001$ \\
\hline
\end{tabular}

\section{Discussion}

This study aimed to assess the impact of three years of community-based comprehensive HIV prevention intervention on the sexual behaviour of oil and gas workers in Bonny Island, a rural community of Rivers
State, Nigeria. This is vital to the control of HIVIAIDS and other STIs in Nigeria and other low-and-middleincome countries.

Unprotected sexual intercourse is among the commonest routes of HIV transmission in developing 
countries like Nigeria, especially in rural communities. ${ }^{1}$ Consistent use of condom is a widely known appropriate behavioural pointers used to assess the success of HIV-control interventions, particularly among the key populations. ${ }^{13}$

This study found a very high rate $(82.1 \%)$ of unprotected sex in the community before the health interventions. This rate was drastically reduced below $25 \%$ after the interventions $(p<0.001)$. This reduction can largely be attributed to the interventions in this community. The rate of unprotected sex was found higher among females than in males without intervention. This might be as a result of more married women than men since our study also revealed that the level of unprotected sex, both in three months before the survey and in the last sexual activities was higher in females than in males. There was a significant decline in the rate of unprotected sex among both males and females in the post-intervention $(p<0.001)$ with females having a lower rate of unprotected sex. This can be attributed to the level of awareness education intensified through radio and television programs as wells as town hall meetings, flier's distribution and free distribution of condoms. Studies have identified an association between non-use of condom with being female and living with spouses/partners in the last sexual intercourse. ${ }^{1}$ However, our finding (for people without interventions) contrasts the finding of Udoh et al. in Nigeria who reported that more men had unprotected sexual intercourse than women. ${ }^{11}$ Our study only found that more males than females had unprotected sex after the interventions.

Though our findings revealed an increase in the percentage of participants that used condom in their last sexual intercourse from $5 \%$ in baseline to $26.0 \%$ in post-intervention surveys, with those in the postintervention were 6.66 (95\% Cl-4.08-10.88; $\mathrm{P}<0.0001)$ times likely to use condoms more than their baseline counterparts. A meta-analysis study conducted in Nepal showed a similar improvement in the use of condom due to exposure to behavioural interventions in both vaginal and anal intercourse. ${ }^{13}$ However, the improvement is still low though our study could not establish whether the intercourse was with regular partners or sex workers. This low level of condom usage in the rural community emphasises the need for more and regular interventions. The low uptake of condom is not peculiar to Bonny Island because several other studies have reported low levels of condom usage, particularly without intervention. ${ }^{18,19,24,25}$ In a similar study to characterize unsafe sexual behaviour among factory workers in Northern Vietnam, it was found that the use of condom among the workers in the last sexual intercourse was very low, regardless of whether the sexual intercourse was with casual partners or sex workers. ${ }^{1}$ Another study conducted in Jordan among factory workers reported that just $2.1 \%$ used condoms with regular partners during the most recent sexual intercourse and $27.7 \%$ reportedly used condoms with non-regular sexual partners. ${ }^{26}$

Other factors associated with unprotected sexual intercourse in this study include having stayed in the community for four years or more, not living with spouses in the community and not seeing spouse more than once in a month. These findings are in agreement with previous studies from different part of the world. ${ }^{1,10,26-28}$ Similar to the findings of this study, improved usage of a condom due to intervention had previously been reported in sub-Saharan Africa, India, and Vietnam. , 10,29,30 $^{2}$

This study found a significant decline in the percentage of respondents who exchange sex for gifts from $14.6 \%$ at baseline to $12.4 \%$ after the intervention $(P<0.0001)$. Those that exchanged sex for money or other gifts in both surveys were mostly females and singles, uneducated and those who were separated from their spouses for at least 12 months including those who did not see their spouses more than once in a month. The proportion of the respondents who exchanged sex for gift /money in our study is lower than the $27.5 \%$ baseline and $24.2 \%$ post-intervention seen in Ilorin, Nigeria. ${ }^{31}$ Some studies have also shown that single women (adolescents) are powerless to negotiate the desired outcome of sexual intercourse when money and gifts are exchanged. ${ }^{32}$ This inability to negotiate sexual intercourse when gifts are involved may be responsible for the high rate of exchange for money among young people. As seen in this study, lack of proper education and being unmarried are other factors that have been reported to influence the high rate of transactional sex in Nigeria. ${ }^{33,34}$ Studies have also revealed that women engage in sexual favours for a material benefit ${ }^{5}$ and this had been described as the result of poverty and financial and material reliance of women on men, which limit their negotiation for safer sex. ${ }^{35}$ Similar to our findings, exchange for gifts money for sex has been found in rural areas ${ }^{4}$ because most of the wealthy workers of oil and gas industries migrate to 
Sexual Behaviours among Oil and Gas Workers in the Niger-Delta Region of Nigeria: Assessing the Impact of ...

the Niger-Delta region without their families, they use their wealth to entice the poor villagers to engage in unsafe sexual activities with them. ${ }^{12}$ This underscores the need for community-based sensitisation and enlightenment interventions towards the prevention of diseases and unwanted pregnancies.

The limitations to this study are, first, with the use of surveys and self-reporting information which may be biased. Second, due to the migration of workers, the proportion of the baseline respondents who participated in the post-intervention survey may be small since this study did not have any means to identify the baseline respondents, this may limit the detection of a difference in sexual behaviour of the oil and gas workers.
However, only oil and gas workers who participated in the intervention programs and presented for HIV counselling and testing were allowed in the study.

\section{Conclusion}

This study found a significant positive impact of a comprehensive intervention programme on the sexual behaviour of oil and gas workers in the rural community of Rivers State, Nigeria. There was an improved usage of a condom due to the intervention programs. Also, there was a drop in the level of exchange of gift for sex. However, there is a need for regular interventions in rural communities towards the prevention of the spread of STIs and HIV in Nigeria.

\section{References}

1. Tran $B X$, Vo $T$, Dang AK, Nguyen $Q N, V u G T, V u$ $L G$, et al. Characterizing unsafe sexual behavior among factory workers in the context of rapid industrialization in Northern Vietnam. International Journal of Environmental Research Public Health. 2019;16(24).

2. Dai W, Gao J, Gong J, Xia X, Yang H, Shen $Y$, et al. Sexual behavior of migrant workers in Shanghai, China Health behavior, health promotion and society. BMC Public Health 15. 2015. 1067. Available from: https://bmcpublichealth.biomedcentral.com/ articles/10.1186/s12889-015-2385-y

3. Global Health Sector Strategy on Sexually Transmitted Infections, 2016-2021. World Health Organization. Geneva, Switzerland.Accessed 2020-07-15; Available at https://www.who.int/ reproductivehealth/publications/rtis/ghss-stis/en/

4. Farzi N, Karmi S. Universal health coverage - There is more to it than meets the eye. J Fam Med Prim Care 2017;6(2):169-70. Available from: http://www. jfmpc.com/article. asp?issn=2249-4863;year $=2017 ; \mathrm{v}$ olume $=6 ;$ issue $=1 ;$ spage $=169 ;$ epage $=170 ;$ aulast $=$ Fai zi

5. Udoh IA, Mantell JE, Sandfort T, Eighmy MA. Potential pathways to HIVIAIDS transmission in the Niger Delta of Nigeria: Poverty, migration and commercial sex. AIDS Care - Psychol Socio-Medical Asp AIDS/HIV 2009;21(5):567-74.

6. Consolidated guidelines on HIV prevention, diagnosis, treatment and care for key populations. World Health Organization. Geneva. Switzerland. 2014. Available from: http://apps.who.int/iris/ bitstream/10665/128048/1/9789241507431_eng. pdf?ua $=1$

7. Mucci N, Traversini V, Giorgi G, Garzaro G, FizPerez J, Campagna M, et al. Migrant Workers

and physical health: An umbrella review. Sustain 2019;11(1):232. Available from: https://www.mdpi. com/2071-1050/11/1/232\#cite

8. Gruber E, Grube JW. Adolescent sexuality and the media: a review of current knowledge and implications. West J Med. 2000;172(3):210-214.

9. HIV prevention programmes overview. Glob Inf Educ HIV AIDS 2019. AVERT. United Kingdom. [Accessed 2020 Apr 10]; Available from: https://www.avert.org/ professionals/hiv-programming/prevention/overview

10. Arora V, Sharma S, Mahashabde P. Sexual behavior among migrant construction workers in Indore. Int J Med Sci Public Heal 2014;3(5):574-77.

11. Udoh Sb, Idung Au. Sexual Practices, Knowledge and Prevention of Sexually Transmitted Diseases among Upper Grade Secondary School Adolescent Students in Uyo, Nigeria. IOSR Journal of Dental and Medical Sciences. 2015;14(4):9-15.

12. Udonwa NE, Ekpo M, Ekanem IA, Inem VA, Etokidem A. Oil doom and AIDS boom in the Niger Delta Region of Nigeria. Rural Remote Health 2004;4(2):273.

13. Deuba K, Sapkota D, Shrestha U, Shrestha R, Rawal $\mathrm{BB}$, Badal K, et al. Effectiveness of interventions for changing HIV related risk behaviours among key populations in low-income setting: A Meta-Analysis, 2001-2016. Sci Rep 2020;10(1):2197

14. Khawcharoenporn T, Srirach C, Chunloy K. Educational Interventions Improved Knowledge, Attitude, and Practice to Prevent HIV Infection among HIV-Negative Heterosexual Partners of HIV-Infected Persons. J Int Assoc Provid AIDS Care 2020;19. Available from : https://www.ncbi.nlm.nih.gov/pmc/ articles/PMC6971971/

15. Wang G, Wada K, Hoshi K, Sasaki N, Ezoe S, Satoh T. Association of Knowledge of HIV and Other Factors with Individuals' Attitudes toward HIV Infection: A National Cross-Sectional Survey among 
the Japanese Non-Medical Working Population. PLoS One 2013;8(7):e69495. Available from : https:// pubmed.ncbi.nlm.nih.gov/23874644/

16. Ugarte WJ, Högberg U, Valladares E, Essén B. Assessing knowledge, attitudes, and behaviors related to HIV and AIDS in Nicaragua: A communitylevel perspective. Sex Reprod Healthc 2013;4(1):3744.

17. Ikpeazu A, Momah-Haruna A, Mari BM, Thompson LH, Ogungbemi K, Daniel U, et al. An appraisal of female sex work in Nigeria - Implications for designing and scaling up HIV prevention programmes. PLoS One 2014;9. Available from : https://journals.plos.org/ plosone/article?id=10.1371/journal. pone.0103619.

18. Sani AS, Abraham C, Denford S, Ball S. School-based sexual health education interventions to prevent STI / HIV in sub- Saharan Africa : a systematic review and meta-analysis. BMC Public Health 2016 : 1069. Available from: http://dx.doi.org/10.1186/s12889016-3715-4

19. Scott-Sheldon L, Walstrom P, Harrison A, Kalichman S, Carey M. Sexual Risk Reduction Interventions for HIV Prevention among South AfricanYouth: A MetaAnalytic Review. Curr HIV Res 2014;11(7):549-58.

20. Onoja A, Sanni F, Onoja S, Adamu I, Shaibu J, Abiodun P. Impact of health interventions on the knowledge, perception, attitude, and misconception of HIV infection in an African rural community. International Journal of Medicine and Health Development. 2021;26(2):91-98

21. Johnson A, Sheila O, Imam O, Paul A, Abiodun $\mathrm{O}$, Shaibu J, et al. Baseline and Post-intervention Surveys of the Prevalence of HIV in an African Rural Population and Women in the Brothel. International Archives of Health Scienc 2020;7(4):176-81.

22. Johnson A, Sheila O, Imam O, Paul A, Abiodun $\mathrm{O}$, Shaibu J, et al. Baseline and Post-Intervention Assessment of Knowledge, Accessibility and Condoms Use in an African Rural Community. Journal of Middle East and North Africa Sciences. 2020; 2020;6(06):32-40.

23. Thurman TR, Kidman R, Carton TW, Chiroro P. Psychological and behavioral interventions to reduce HIV risk: evidence from a randomized control trial among orphaned and vulnerable adolescents in South Africa. AIDS Care 201, 28( sup1):8-15. Available from: http://dx.doi.org/10.1080/09540121. 2016.1146213

24. Ojo O, Verbeek JH, Rasanen K, Heikkinen J, Isotalo LK, Mngoma N, et al. Interventions to reduce risky sexual behaviour for preventing HIV infection in workers in occupational settings. Cochrane Database Syst Rev 2011;(12). Available from : https://pubmed. ncbi.nlm.nih.gov/22161391/
25. Al Rifai R, Nakamura K, Seino K, Kizuki M, Morita A. Unsafe sexual behaviour in domestic and foreign migrant male workers in multinational workplaces in Jordan: Occupational-based and behavioural assessment survey. BMJ Open 2015;5 :e007703.

26. Shen $Q$, Wang $Y$, Wang Z, Wang $Y$, Luo $M$, Wang $S$, et al. Understanding condom use among unmarried female migrants: A psychological and personality factors modified information-motivationbehavioral skills model. BMC Public Health 19. 2019; 223. Available from : https://bmcpublichealth. biomedcentral.com/articles/10.1186/s12889-0196541-7.

27. Pham KTH, Nguyen LH, Vuong QH, Ho MT, Vuong TT, Nguyen HKT, et al. Health inequality between migrant and non-migrant workers in an industrial zone of Vietnam. International Journal Environment Res Public Health 2019;16(9): 1502. Available from : https://pubmed.ncbi.nlm.nih.gov/31035337/

28. Sahile Z, Mekuria M, Yared A. Comprehensive HIVIAIDS Knowledge and Sexual Behavior among University Students in Ambo, Central Ethiopia: Implication to Improve Intervention. Journal of Sexually Transmitted Diseases 2015;(2015):890202. Available from : https://www.ncbi.nlm.nih.gov/pmc/ articles/PMC4477256/.

29. Kharsany ABM, Karim QA. HIV Infection and AIDS in Sub-Saharan Africa: Current Status, Challenges and Opportunities. The Open AIDS Journal. 2016;10(1):34-48.

30. Aderibigbe SA, Araoye MO. Effect of health education on sexual behaviour of students of public secondary schools in Ilorin, Nigeria. European Journal of Scientific Research. 2008;24(1):33-41.

31. Thomas SL. Wakerman J. Humphreys JS. What core primary health care services should be available to Austrailians living in rural and remote communitites? BMC Family Practice. 2014.(15) Available from : Aust Nurs J 2010;18(5):1.

32. HIV prevalence and sexual behaviours of persons with disabilities in Nigeria. 2015. Enhacing Nigeria's HIVIAIDS Response Programe. Available from : https://www.popcouncil.org/uploads/pdfs/2015HIV_ ENR-PersonsWithDisabilities.pdf

33. Eluwa GI, Strathdee SA, Adebajo SB, Ahonsi B, Azeez A, Anyanti J. Sexual risk behaviors and HIV among female sex workers in Nigeria. J Acquir Immune Defic Syndr 2012;61(4):507-14.

34. Wamoyi J, Wight D, Plummer M, Mshana GH, Ross D. Transactional sex amongst young people in rural northern Tanzania: An ethnography of young women's motivations and negotiation. Reprod Health 2010.29;7:2. 